\title{
ASSESSMENT OF PAIN IN VENTILATED ICU PATIENTS USING BEHAVIORAL PAIN SCALE
}

\author{
Nidhin ${ }^{1}$, Syed Fazal Mahmood ${ }^{2}$, S. Padmanabha ${ }^{3}$ \\ 1 Post Graduate Trainee, Department of Anaesthesia, Yenepoya Medical College, Mangalore. \\ ${ }^{2}$ Post Graduate Trainee, Department of Anaesthesia, Yenepoya Medical College, Mangalore. \\ 3 Professor and HOD, Department of Anaesthesia, Yenepoya Medical College, Mangalore.
}

\section{ABSTRACT}

Systematic assessment of pain is difficult in intensive care units, because most of the patients are non-communicative and are unable to self-report pain. The Behavioral Pain Scale (BPS) is one of the assessment tools for uncommunicative and sedated intensive care unit patients. This study is to assess and evaluate the efficacy and reliability of BPS scale in mechanically ventilated patients.

\section{MATERIALS AND METHODS}

Prospective observational study in 71 mechanically ventilated medical ICU patients who were unable to report pain was assessed with BPS.

\section{RESULTS}

Post procedure there was a significant difference in the percentage of patients with an increased BPS score for repositioning, but not for oral care.

\section{CONCLUSIONS}

This study showed that the BPS is reliable and valid for use in sedated ICU patients. We conclude that pain scales should be incorporated into pain management as protocols to target the desired levels of analgesia in order to optimize inter-professional practices and to achieve better patient outcomes.

\section{KEYWORDS}

Behavioral Pain Scale, Mechanical Ventilation, In ICU Pain Assessment.

HOW TO CITE THIS ARTICLE: Nidhin, Syed Fazal Mahmood, S. Padmanabha. "Assessment of Pain in Ventilated ICU Patients using Behavioral Pain Scale." Journal of Evolution of Medical and Dental Sciences 2015; Vol. 4, Issue 101, December 17; Page: 16688-16690, DOI: $10.14260 /$ jemds/2015/2493

\section{INTRODUCTION}

Pain is a common and distressing symptom in ICU patients. ${ }^{1}$ Systematic assessment of pain is difficult in ventilated patients, because they are non-communicative and are unable to self-report pain. Major challenge exists in assessing and evaluating the pain in ventilated patients. Although the patient's self-report of pain is the "Gold standard" for pain assessment, other methods must be considered when patients are unable to self-report because of the sedatives and analgesics.

Approximately, $50 \%$ of the patients reports moderateto-severe pain, both at rest and during routine procedures. ${ }^{2}$ Untreated acute pain in adult ICU patients has short- and longterm physiological and psychological consequences such as postoperative myocardial infarction, insufficient sleep and the risk of developing a post-traumatic stress disorder.

The consequences of inadequate control of pain are significant, but excessive use of analgesics and sedation can lead to unwanted side effects such as hypoventilation, gastrointestinal hypomotility, gastric bleeding and renal

Financial or Other, Competing Interest: None.

Submission 23-11-2015, Peer Review 24-11-2015,

Acceptance 10-12-2015, Published 17-12-2015.

Corresponding Author:

Dr. Syed Fazal Mahmood,

Department of Anaesthesia

Yenepoya Medical College,

Mangalore, Karnataka.

E-mail: lazaf4u@gmail.com

DOI:10.14260/jemds $/ 2015 / 2493$ dysfunction as a result of all these and to reduce the intraintensive care unit stay, pain during mechanical ventilation has to be assessed and controlled.

There are various ways to assess pain in mechanically ventilated patients. Behavioural Pain Scale (BPS) is one of the popular tool to measure pain in ventilated patients. In this study, we assess the credibility of BPS in measuring pain in mechanically ventilated patients.

\section{METHODOLOGY}

This study was conducted in a Tertiary Care ICU, a total of 71 patients were studied and all patients were between the age group of 18-70 years and were mechanically ventilated for more than 48 hours. All patients were haemodynamically stable. Patients with neurological deficits and patients receiving neuromuscular blocking agents were excluded from this study.

The BPS developed by Payen et al. (2001) was used to assess pain in unconscious mechanically ventilated patients. The BPS is based on the sum score of three behavioural expressions: facial expressions, upper limb movements and compliance with mechanical ventilation. The BPS allows the observer to derive a score between 3 (No pain) and 12 (Highest pain score).

Two procedures were used for the assessment of pain using the BPS tool. The painful procedure of repositioning was identified from the literature. Oral care which consisted of a simple oral suctioning normal saline and suction catheter was taken as non-painful. 
As all patients were unconscious, written consent was obtained from the patient's relatives prior to data collection. The research resident was trained in the use of the BPS tool. Patients undergoing routine procedures of repositioning and oral suctioning were assessed within a 48-hour period. The research resident would confer with the primary nurse to ascertain when the oral care and repositioning procedures were to be carried out. The research resident would then return at those times to observe the patient having the procedure performed. Data was collected during rest, oral suctioning and during repositioning.

The validity of the BPS was assessed in terms of construct validity, where the BPS accurately measured the construct of pain. Specifically, whether the BPS was able to detect increases in pain after a routine painful procedure and demonstrate no change after a non-painful procedure. Paired ' $\mathrm{T}$ ' test was used to analyze statistically significant results.

\section{RESULTS}

Seventy one intubated and mechanically ventilated patients were included in this study, of which $56.33 \%$ (40) were males and $43.67 \%$ (31) were females and the median age was 64 years (Range $=18-70$ years). The majority were medical patients with only 20 patients having undergone a surgical procedure. Diagnoses varied greatly from pneumonia and asthma to polytrauma.

All patients were assessed at rest, repositioning and oral care procedure, the mean BPS values indicate that there were no differences in pain levels prior to the procedures being undertaken (See Table 1). Increases in mean pain scores were observed after oral care and repositioning, but the mean score after repositioning was significantly high (See Table 2).

\begin{tabular}{|c|c|c|c|c|}
\hline \multicolumn{5}{|c|}{ Paired Samples Statistics } \\
\hline \multicolumn{2}{|c|}{} & Mean & N & $\begin{array}{c}\text { Std. } \\
\text { Deviation }\end{array}$ \\
\hline \multirow{2}{*}{ Pair 1 } & REST & 3.46 & 71 & .556 \\
\cline { 2 - 5 } & ORAL CARE & 5.86 & 71 & 1.257 \\
\hline \multirow{3}{*}{ Pair 2 } & ORAL CARE & 5.86 & 71 & 1.257 \\
\cline { 2 - 6 } & $\begin{array}{c}\text { REPOSITIONING } \\
\text { (PAIN) }\end{array}$ & 10.69 & 71 & 1.190 \\
\hline \multirow{3}{*}{ Pair 3 } & REST & 3.46 & 71 & .556 \\
\cline { 2 - 6 } & $\begin{array}{c}\text { REPOSITIONING } \\
\text { (PAIN) }\end{array}$ & 10.69 & 71 & 1.190 \\
\hline \multicolumn{5}{|c|}{ Table 1: Paired Sample Statistics } \\
\hline
\end{tabular}

\begin{tabular}{|c|c|c|c|c|c|}
\hline \multicolumn{6}{|c|}{ Paired Samples Test } \\
\hline & & \multicolumn{2}{|c|}{ Paired Differences } & \multirow{2}{*}{$\mathbf{t}$} & \multirow{2}{*}{ Sig. (2-tailed) } \\
\hline & & Mean & Std. Deviation & & \\
\hline Pair 1 & REST - ORAL CARE & -2.394 & 1.368 & -14.750 & $<0.001$ \\
\hline Pair 2 & ORAL CARE - REPOSITIONING(PAIN) & -4.831 & 1.549 & -26.278 & $<0.001$ \\
\hline Pair 3 & REST - REPOSITIONING(PAIN) & -7.225 & 1.289 & -47.214 & $<0.001$ \\
\hline \multicolumn{6}{|c|}{ Table 2: Paired T Test to Compare the Three Pain Scales } \\
\hline
\end{tabular}

Results showed that at post-procedure there was a significant difference in the percentage of patients with an increased BPS score for repositioning, but not for oral care.

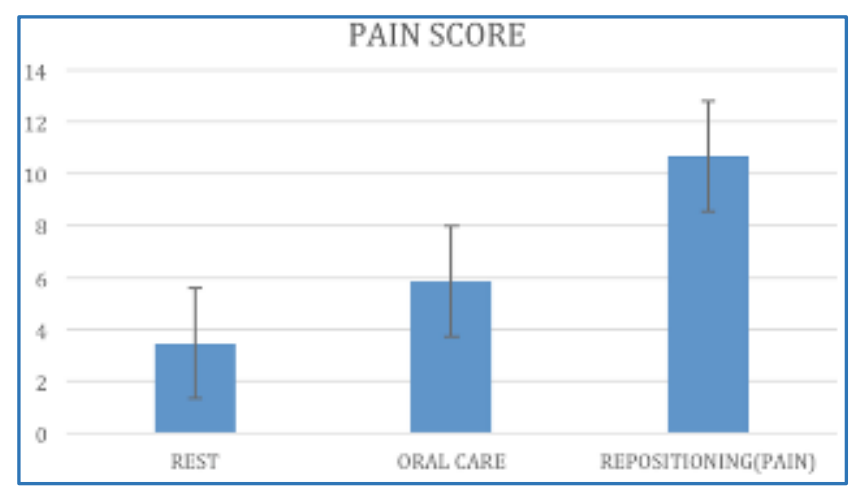

\section{DISCUSSION}

Assessing pain in non-communicative adult patients in the ICU must rely on the observation of behavioral indicators of pain. ${ }^{3}$ Numerous studies have reported the undertreatment of pain in the critically ill conscious patient, very few studies have actually researched how best the pain can be assessed in unconscious, ventilated ICU patient. Systematic evaluation of pain and agitation and analgesics and sedatives need was associated with a decrease in incidence of pain and agitation, duration of mechanical ventilation and nosocomial infections. 4,5 The patients in the intensive care unit who were mechanically ventilated and had to undergo basic minimum procedures like oral care, IV cannulation, ryle's tube insertion and repositioning have to suffer mild-to-severe pain. In this study, we have used BPS to evaluate the pain suffered by ventilated patients in ICU. We have also assessed the credibility of BPS in assessing the pain in ventilated unconscious patients.

In our study, the minimum age was 18 and maximum was 70 years and a median of 64 years. The majority were medical patients with only 20 surgical patients. The patients were assessed with BPS at rest, repositioning and oral care procedure, the mean BPS values indicate that there were no differences in pain levels at rest. Increases in mean pain scores was observed after oral care and repositioning, but the mean score after repositioning was significantly high and these results indicate that the BPS scores were very high during painful procedure, i.e. repositioning. The BPS uses facial expression, movement and compliance with ventilation as behavioural indicators of pain in unconscious sedated patients. Results from this study revealed that the BPS was a valid tool in assessing pain in unconscious critically ill patients. Specifically, the BPS consistently identified increases in pain scores after repositioning, whereas there were only small, non-significant shifts in pain scores after the non-painful oral care procedure. The BPS score at repositioning was 3 times higher than the BPS score at rest.

\section{CONCLUSION}

A total of 71 intubated and mechanically ventilated patients were studied and we concluded that ICU stay is painful both psychologically as well as physically. The results showed that BPS is a valid tool to assess changes in pain level associated with painful routine procedures. Our study strongly argue in favor of the routine use of dedicated instrument, such as 
behavioral pain scale in the intensive care unit and to be routinely utilized to assess both pain and sedation in mechanically ventilated patients.

\section{REFERENCES}

1. Puntillo, Kathleen, Chris Pasero, Denise Li, Richard A Mularski, Mary Jo Grap, et al. "Evaluation of pain in ICU patients.” CHEST Journal 135, no. 4 (2009): 1069-1074.

2. Rijkenberg S, Stilma W, Endeman H, et al. "Pain measurement in mechanically ventilated critically ill patients: Behavioral Pain Scale versus Critical-Care Pain Observation Tool." Journal of critical care 30, no. 1 2015;167-172.
3. Payen, Jean-Francois and Céline Gélinas. "Measuring pain in non-verbal critically ill patients: which pain instrument?" Pain Manag Nurs 9 2008;120-130.

4. Barr, Juliana, Gilles L Fraser, Kathleen Puntillo, Wesley Ely E, Céline Gélinas, et al. "Clinical practice guidelines for the management of pain, agitation and delirium in adult patients in the intensive care unit." Critical care medicine 41, no. 1 2013;263-306.

5. Chanques, Gerald, Samir Jaber, Eric Barbotte, Sophie Violet, Mustapha Sebbane, et al. "Impact of systematic evaluation of pain and agitation in an intensive care unit." Critical care medicine 34, no. 6 2006;1691-1699. 